\title{
Retinoid Hyposignaling Contributes to Aging-Related Decline in Hippocampal Function in Short-Term/Working Memory Organization and Long-Term Declarative Memory Encoding in Mice
}

\author{
Frédérique Mingaud, ${ }^{1,2}$ Cécile Mormede, ${ }^{1,2}$ Nicole Etchamendy, ${ }^{1}$ Nicole Mons, ${ }^{1}$ Betty Niedergang ${ }^{1}$ Marta Wietrzych, ${ }^{3}$ \\ Véronique Pallet, ${ }^{2}$ Robert Jaffard, ${ }^{1}$ Wojciech Krezel, ${ }^{3}$ Paul Higueret, ${ }^{2}$ and Aline Marighetto ${ }^{1}$ \\ ${ }^{1}$ Centre Neurosciences Intégratives et Cognitives, Université Bordeaux 1, Centre National de la Recherche Scientifique, Unité Mixte de Recherche 5228, \\ 33405 Talence, France, ${ }^{2}$ Unité Nutrition et Neurosciences, Université Bordeaux 1-2, 33405 Talence, France, and ${ }^{3}$ Institut de Génétique et de Biologie \\ Moléculaire et Cellulaire, 67404 Illkirch, France
}

\begin{abstract}
An increasing body of evidence indicates that the vitamin A metabolite retinoic acid (RA) plays a role in adult brain plasticity by activating gene transcription through nuclear receptors. Our previous studies in mice have shown that a moderate downregulation of retinoidmediated transcription contributed to aging-related deficits in hippocampal long-term potentiation and long-term declarative memory (LTDM). Here, knock-out, pharmacological, and nutritional approaches were used in a series of radial-arm maze experiments with mice to further assess the hypothesis that retinoid-mediated nuclear events are causally involved in preferential degradation of hippocampal function in aging. Molecular and behavioral findings confirmed our hypothesis. First, a lifelong vitamin A supplementation, like shortterm RA administration, was shown to counteract the aging-related hippocampal (but not striatal) hypoexpression of a plasticity-related retinoid target-gene, GAP43 (reverse transcription-PCR analyses, experiment 1), as well as short-term/working memory (STWM) deterioration seen particularly in organization demanding trials (STWM task, experiment 2). Second, using a two-stage paradigm of LTDM, we demonstrated that the vitamin A supplementation normalized memory encoding-induced recruitment of (hippocampo-prefrontal) declarative memory circuits, without affecting (striatal) procedural memory system activity in aged mice (Fos neuroimaging, experiment 3A) and alleviated their LTDM impairment (experiment 3B). Finally, we showed that (knock-out, experiment 4) RA receptor $\beta$ and retinoid X receptor $\gamma$, known to be involved in STWM (Wietrzych et al., 2005), are also required for LTDM. Hence, aging-related retinoid signaling hypoexpression disrupts hippocampal cellular properties critically required for STWM organization and LTDM formation, and nutritional vitamin A supplementation represents a preventive strategy. These findings are discussed within current neurobiological perspectives questioning the historical consensus on STWM and LTDM system partition.
\end{abstract}

Key words: nutritional supplementation; RAR $\beta / \mathrm{RXR} \gamma$ nuclear receptors; knock-out; GAP43; Fos; proactive; interference; radial arm maze

\section{Introduction}

Most of the vitamin A functions are performed by its metabolite retinoic acid (RA) (Malik et al., 2000; Marill et al., 2003; Blomhoff and Blomhoff, 2006). RA regulates gene expression in numerous cells and tissues by binding to nuclear RA receptors $(\mathrm{RAR} \alpha$, $\operatorname{RAR} \beta$, and $\operatorname{RAR} \gamma)$ and retinoid $X$ receptors $(\operatorname{RXR} \alpha, \operatorname{RXR} \beta$, and $\operatorname{RXR} \gamma$ ), which act as transcription factors (Kastner et al., 1995;

\footnotetext{
Received Feb. 27, 2007; revised 0ct. 23, 2007; accepted Nov. 15, 2007.

This work was supported by the Centre National de la Recherche Scientifique, Conseil Régional d'Aquitaine, Groupement d'Intérêt Scientifique Longevité et Institut de France-Fondation NRJ. E.N. was supported by a Nestle postdoctoral fellowship.

Correspondence should be addressed to Dr. A. Marighetto, Centre Neurosciences Intégratives et Cognitives, Université Bordeaux 1, Centre National de la Recherche Scientifique, Unité Mixte de Recherche 5228, 33405 Talence, France. E-mail: a.marighetto@cnic.u-bordeaux1.fr.

D0I:10.1523/JNEUROSCI.4065-07.2008

Copyright $\odot 2008$ Society for Neuroscience $\quad$ 0270-6474/08/280279-13\$15.00/0
}

Lefebvre et al., 2005). Retinoid signaling is well known to be involved in brain development (Maden et al., 1998). It has recently come to light, however, that retinoid signaling continues to play a role in certain areas of the mature brain, by its involvement in cellular and synaptic plasticity processes sustaining learning and memory capabilities (for review, see Mey and McCaffery, 2004; Lane and Bailey, 2005; McCaffery et al., 2006).

Functional implication of retinoid signaling in hippocampal plasticity and spatial memory was demonstrated in rodents by knock-out of $\operatorname{RAR} \beta$ or $\operatorname{RXR} \beta / \gamma$ receptors (Chiang et al., 1998; Wietrzych et al., 2005), vitamin A deprivation (Misner et al., 2001; Cocco et al., 2002; Etchamendy et al., 2003b), and RA administration (Crandall et al., 2004). Furthermore, dysfunction of retinoid signaling pathway has been hypothesized to be involved in human neurodevelopmental pathologies such as schizophrenia or late-onset Alzheimer's disease (for review, Goodman, 
1998, 2006; Goodman and Pardee, 2003; Palha and Goodman, 2006).

We previously demonstrated that pharmacological activation of retinoid signaling by short-term RA administration to aged mice restored their hippocampal retinoid target-gene hypoexpression as well as their long-term declarative memory (LTDM) and hippocampal long-term potentiation deficits (Etchamendy et al., 2001). Conversely, nutritional vitamin A deficiency in young mice produced an LTDM impairment like the one observed in aged or hippocampectomized (Etchamendy et al., 2003a,b) mice. These findings (see also Brouillette and Quirion, 2007) suggest that retinoid hyposignaling may contribute to aging-related deterioration of hippocampal function (for review, see Rosenzweig and Barnes, 2003; Driscoll and Sutherland, 2005). The present work was aimed at further assessing this hypothesis by using knock-out, pharmacological, and nutritional approaches.

Prompted by a recent literature questioning the historical partition between LTDM and short-term/working memory (STWM) systems (for review, see Blumenfeld and Ranganath, 2007), we recently showed that the LTDM deficit seen in aged mice was secondary to an STWM impairment at encoding in association with hippocampal (and prefrontal) dysfunction (our unpublished data). We speculated that faster decay of incoming event traces in (hippocampo-prefrontal) short-term episodic buffer may hinder relational encoding of temporally discontiguous events into a unified mnemonic representation sustaining LTDM (Wallenstein et al., 1998; Eichenbaum, 2004; Mingaud et al., 2007).

Here we demonstrated that $\operatorname{RAR} \beta / \operatorname{RXR} \gamma$, which were shown previously to be involved in STWM (Wietrzych et al., 2005), are required for LTDM and that, like RA treatment, nutritional vitamin A supplementation prevents the age-related decline in both STWM and LTDM performances, as well as in molecular markers of hippocampal function. The present findings support the hypothesis that hippocampal retinoid receptor signaling is critically implicated in cellular mechanisms sustaining STWM organization and LTDM formation.

\section{Materials and Methods \\ Animals}

In all aging experiments, subjects were naive male mice of the C57BL/6 Jico inbred strain obtained from Janvier (Le Genest-Saint-Isle, France) at the age of 2 months. The RAR $\beta /$ RXR $\gamma$ knock-out mice were produced by crosses of double heterozygous mice as described previously (Wietrzych et al., 2005). All mice were socially housed in standard conditions: room temperature $\left(23^{\circ} \mathrm{C}\right), 12 \mathrm{~h}$ light/dark cycle, and ad libitum food and water. For aging experiments, mice were used when they were 4-5 months (young), 11-12 months (middle-aged), or 21-23 months (aged) old. $\operatorname{RAR} \beta / \operatorname{RXR} \gamma$ double knock-out mice were tested at the age of $4-5$ months.

Experiments were performed in accordance with the European Communities Council Directive of November 24, 1986 (8616091 EEC).

\section{Diets}

For aging experiments, half the animals were fed with a control diet (5 IU retinol/g), which was the same as those described previously (Husson et al., 2003); the second half received the vitamin A-enriched diet (45 IU retinol/g). The composition of the control diet was the same as the vitamin A-enriched diet, excepted for retinol content. The 45 IU diet was chosen on the basis of literature (Zolfaghari and Ross, 1995; Ross and Zolfaghari, 2004) as a moderate supplementation to avoid potential toxicity of hypervitaminosis (for review, see Penniston and Tanumihardjo, 2006). Diets started as soon as mice arrived in the laboratory (i.e., at the age of 2 months) and continued throughout the entire experiment.

\section{RA treatment}

Retinoic acid (Sigma, St. Louis, MO) was dissolved in a vehicle solution containing polyethylene glycol, $\mathrm{NaCl}(0.9 \%)$, and ethanol mixed in a proportion of 70:20:10 by volume. RA was administered subcutaneously, once a day ( $\sim 6: 00$ P.M. to 7:00 P.M.) during 3 weeks at 150 $\mu \mathrm{g} \cdot \mathrm{kg}^{-1} \cdot \mathrm{d}^{-1}$. We showed previously that RA administered in the same way to aged mice was able to restore retinoid signaling expression, CA1 long-term potentiation efficacy, and LTDM to presenescent (adult) levels. Moreover, we demonstrated that these beneficial effects of RA were mediated by RA nuclear receptors because they were abolished by the coadministration of an RAR antagonist (Etchamendy et al., 2001). Accordingly, the rationale for using subcutaneous injections of RA either alone or in combination with vitamin A supplementation was to determine whether the effects of supplementation was mediated via brain retinoid receptors, thereby occluding the effects of RA.

\section{Reverse transcription-PCR analysis of retinoid genes expression \\ Selection of genes and brain structures}

The mRNA coding for two retinoic acid receptors $\operatorname{RAR} \beta$ and $\operatorname{RXR} \beta / \gamma$, and GAP 43, the transcriptional target of retinoid receptor signaling, were measured in samples of the hippocampus and striatum.

Hippocampus and striatum were chosen among the adult brain areas in which retinoid signal is likely to play a role (for review, see Lane and Bailey, 2005) for the following reasons. First, each structure is known to be involved in working memory through its interactions with prefrontal cortex (Newman and Grace, 1999). Second, they are key structures of distinct long-term memory systems (declarative and procedural memory, respectively) (for review, see White and McDonald, 2002) that are known to be differentially affected by aging.

RARs are specific of the retinoid pathway, whereas RXRs are not specific because they heterodimerize with other nuclear receptors such as those for thyroid hormone and vitamin D (Kliewer et al., 1992), as well as the peroxisome proliferator-activated receptor-type receptors (Keller et al., 1993) and can function in the absence of ligand (Rowe, 1997). As members of each category, $\operatorname{RAR} \beta$ and $\operatorname{RXR} \beta / \gamma$ genes were chosen because knock-out studies and our previous work in aged mice have demonstrated their functional implication in hippocampal plasticity and learning and memory.

Neuromodulin GAP43 was chosen as a functional indicator of retinoid signaling expression because it is a plasticity-related gene, and its expression appears to be specifically regulated by retinoid receptors (Taneja et al., 1995; Encinas et al., 2000; Anderson et al., 2001).

\section{Biochemical procedure}

Mice were killed by decapitation. Their hippocampi and striata were removed and stored at $-80^{\circ} \mathrm{C}$. Extraction of RNA was conducted using an extraction kit (RNAplus; Q.BIO Gene, Illkirch, France).

The preparation of cDNA and quantification of mRNA by reverse transcription (RT)-PCR were performed as described previously (Husson et al., 2003). The forward and reverse primers for glyceraldehyde-3phosphate dehydrogenase (housekeeping gene) and for $\operatorname{RAR} \beta$ and $\operatorname{RXR} \beta / \gamma$ were the same as those used previously (Boucheron et al., 2006). For GAP43, the primers were as follows: GAP43 forward, GTGATGCACCAGCTGCTGAGG; reverse, GGGGAGTTATCAGTGGTAGC.

\section{Behavioral testing}

\section{The different types of memory tested}

As a form of short-term memory, working memory temporarily stores information provided by an environmental cue for the execution of an act in the near term (Baddeley and Hitch, 1974). It comprises a maintenance and organizational component.

Long-term memory is classically divided into declarative and procedural memory. In humans, declarative memory is the memory of facts and events that can be consciously remembered and explicitly expressed. Procedural memory consists in bias and habits, which are most of the time acquired by repetition and expressed automatically. Flexibility is a 
cardinal property of declarative memory (Cohen, 1984) that can be assessed in animals.

\section{Apparatus}

Apparatus was a fully automated, elevated and open eight-arm radial maze, the dimensions and construction of which have been described previously (Marighetto et al., 1999). The movement of each door, located at the entrance to each arm, is controlled by a computer program that continuously tracks the position of the subject within the maze. This enables a real-time control of the accessibility to the maze arm(s) according to a predetermined test schedule.

\section{Habituation}

Mice were put on a food restriction diet so that their individual body weights were reduced to and maintained at $88-85 \%$ of the ad libitum weights. Before behavioral testing, they were habituated to the apparatus over $2 \mathrm{~d}$ by allowing them free exploration until all the food pellets in the food well of each arm were collected.

\section{The STWM memory task}

Each mouse was separately assigned six arms, which were grouped into three pairs of adjacent arms (A, B, and C). Each training session consisted of repeated alternate presentations of these pairs and taxed the shortterm retention of arm visits made during preceding trials. Indeed, the location of food among the two arms varied according to an alternation rule between successive trials: on each trial, one pair of arms was opened and the baited arm was the one that has not been visited during the preceding trial with the same pair. Therefore, the mouse had to remember which arm of a given pair was visited in a particular trial until the next presentation of this pair to alternate its choices among successive presentations of the same pair (Fig. 1). As soon as the mouse had reached the end of the chosen arm, the door of the alternative arm was closed. When back onto the central platform, the door of the chosen arm was closed and the mouse was confined there for $10 \mathrm{~s}$ before the next trial (intertrial interval).

Each daily session of working memory testing comprised 23 trials (seven to eight presentations of each pair). The first three trials of each session consisted of acquisition trials: for each pair (A, B, and C), both arms were baited. Each of the following trials was, at the same time, a memory test trial (recall of the arm visit made during the preceding trial with the same pair) and an acquisition trial (for the following test trial with the same pair).

Mice were submitted to 18 consecutive daily sessions of such STWM testing

Correct/incorrect response. Correct/incorrect response was recorded for each trial. Performance was averaged by blocks of three consecutive sessions to analyze the effect of training. For studying STWM maintenance and organizational components, the effects of retention interval and proactive interference levels were analyzed respectively.

Retention interval. Because three pairs were used concurrently, the memory interval for one specific arm-visit retention depended on the number of intervening trials (with the other pairs) occurring between the acquisition trial and the test trial. Hence, correct responses were expected to decrease as the number of intervening trials increased between two successive presentations of the same pair. To analyze this effect, performances were averaged by trials of retention interval levels: "short" (zero intervening trial between the acquisition trial and the test trial), "medium" (one to two intervening trials), and "long" (three to four intervening trials).

Proactive interference/STWM organization. Given that the same three pairs were reused seven to eight times with a session, proactive interference was potentially produced by preceding trials. Specifically, at any one $n$ trial, the mouse had to recall the specific arm visit made in the $n$ - 1 trial with the same pair and not to confound it with the visit made in the $n-2$ trial with the same pair. Proactive interference level depended on the distance between the interfering trial, $n$-2, and the to-be-remembered trial, $n$-1: the shorter the distance, the higher the probability of proactive interference. To analyze such potential effects, performances were averaged by trials of proactive interference (PI) levels: "low PI" (big distance
1: SHORT-TERM/WORKTNG MEMORY (STWM)
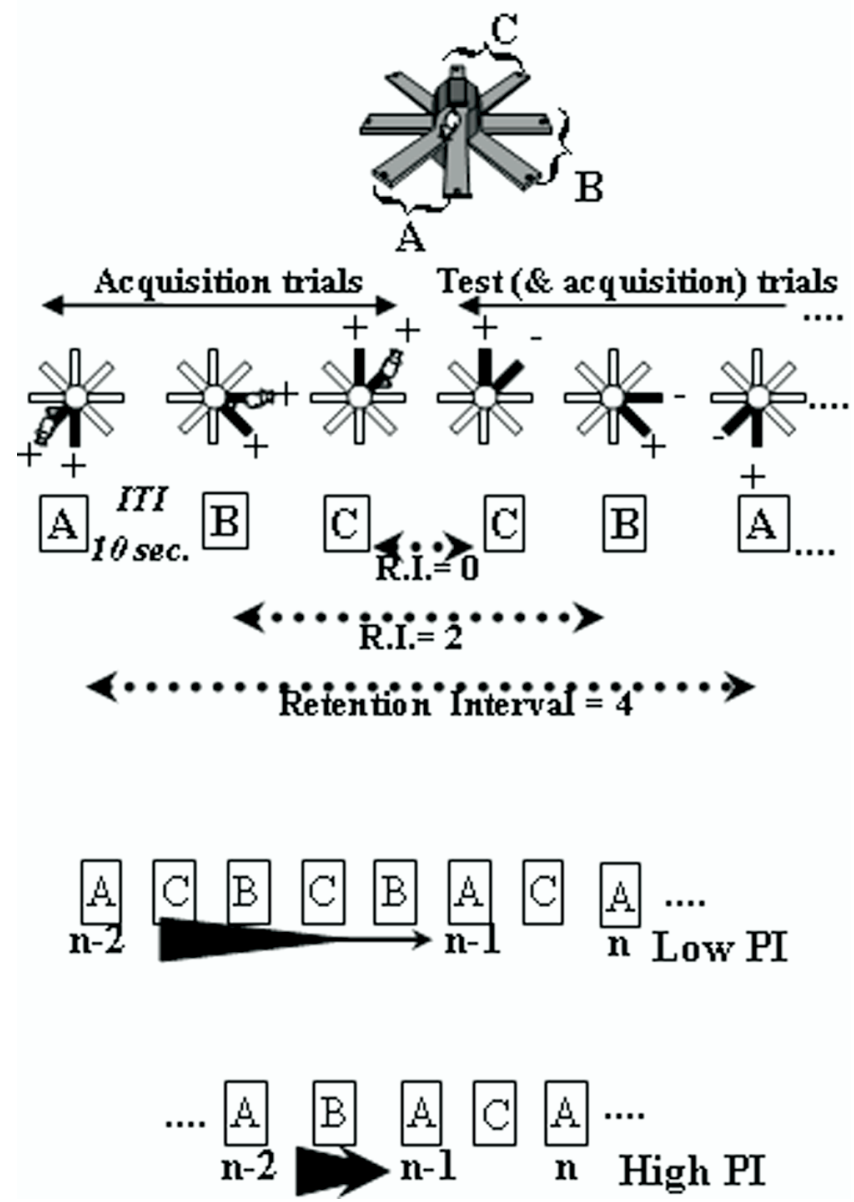

Figure 1. The STWM task. Each session consisted of alternate presentations of pairs A, B, and C. The first three trials with each pair were acquisition trials (both arms rewarded). Each of the following trials was at the same time an acquisition trial (for the following trial with the same pair) and a test trial (for the arm visit made during the preceding trial with the same pair); the rewarded arm was the one that has not been visited on the preceding trial with the same pair. Memory demand varied across successive trials according to the retention interval (i.e., the number of intervening trials with other pairs between two successive presentations of the same pair). Three retention interval levels were distinguished: short ( 0 intervening trial), medium (1-2 intervening trials), and long (3-4 intervening trials). Organizational demand varied across trials according to proactive interference level [i.e., the number of intervening trials between the to-be-remembered trial $(n-1)$ and the interfering trial $(n-2)$ : the more trials between them, the lower the proactive interference effect $]$; two proactive interference levels were distinguished: low PI ( $3-4$ trials between $n-2$ and $n-1)$ and high PI ( $0-1$ trial between $n-2$ and $n-1)$

between $n$-2 and $n$-1: three to four trials were interposed) and "high PI" (short distance between $n$-2 and $n$-1: zero to one trial was interposed).

\section{The LTDM task: a two-stage discrimination learning paradigm} assessing memory flexibility

A two-stage discrimination learning paradigm used in our previous study on retinoid signaling function in aging (Etchamendy et al., 2001) was used again here. This paradigm comprises an initial learning phase (stage 1, encoding) followed by a test phase (stage 2) assessing flexibility, a cardinal property of declarative memory. Flexibility is exemplified in the ability to compare and contrast separately acquired information to guide inferential decision in novel situations (Cohen, 1984). In stage 1 , the mice learn the constant locations of food reward through successive and separate exposures to individual arms using a "go/no-go" discrimination procedure. In stage 2 , they are challenged with novel arm presen- 


\section{2: LONG-TERMDECLARATIVE MEMORY (L TDM)}

\author{
Stage 1: Acquisition \\ successive "go/no-go" discrimination
}
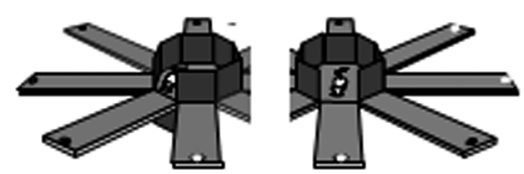

Inter-Trial Interval:20 sec.

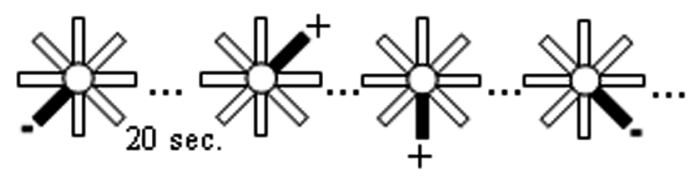

Stage 2: Flexibility test simultaneous "two-choice" discrimination
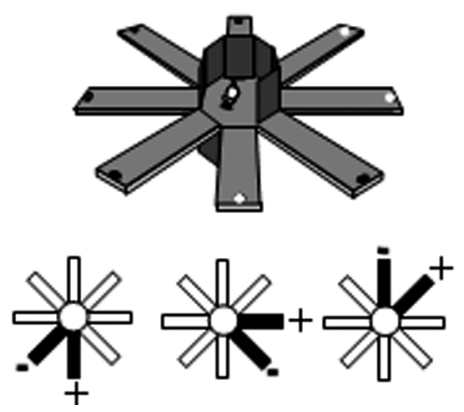

Figure 2. The LTDM paradigm. In stage 1, the six arms were presented one by one, successively; in stage 2, the same arms were combined into three pairs. Stage 2 testing assesses memory flexibility exemplified in the ability to compare and contrast information pieces that were acquired separately.

tations that require explicit choices among adjacent arms that were experienced separately in stage 1 and are now presented by pairs (simultaneous "two-choice" discrimination test).

Each mouse was separately assigned six adjacent arms of the radial maze. The reward valence of the arms (three baited, three nonbaited) remained constant throughout the experiment, but the manner of presenting the arms to the mouse (i.e., one-by-one vs by pair presentation) was changed between the two stages of the experiment (Fig. 2).

Stage 1 (encoding): acquisition of successive go/no-go discrimination between rewarded and nonrewarded arms. On each trial, the door to only one arm was opened and the latency to enter the arm was automatically recorded. Each daily session comprised 24 trials, with each of the six arms presented four times according to a pseudorandomized order. The mouse was confined on the central platform for $20 \mathrm{~s}$ between successive trials. Consecutive daily training continued until achievement of criterion performance, when the median latency to enter nonbaited arms exceeded that to the baited ones by $25 \%$ in the last $2 \mathrm{~d}$. For statistical analysis, go/no-go discrimination performance was indexed by a normalized discriminative ratio: (latency for nonbaited - latency for baited) $/$ (latency for nonbaited + latency for baited).

Stage 2 (test): simultaneous two-choice discrimination assessing mnemonic flexibility (i.e., LTDM). On each trial, one of the three possible pairs of adjacent arms (one baited, one nonbaited) was opened, and the mouse was required to enter one of the two arms. As soon as the mouse reached the end of the chosen arm, the door to the alternative arm was closed. On return to the central platform, all doors were closed and the mouse was confined there for $20 \mathrm{~s}$ before the next trial began. There were a total of 20 trials, and performance was indexed by percentage correct choices (of baited arms).

\section{Fos immunohistochemistry}

A neuroimaging approach based on the activity-dependent expression of the Fos protein was used (Morgan and Curran, 1989; McCabe and Horn, 1994; Touzani et al., 2003) to map memory encoding-related patterns of activity in brain areas known to be involved in long-term declarative memory (hippocampus and prefrontal cortex) and procedural memory (dorsal striatum).

Ninety minutes after the last behavioral session, mice were deeply anesthetized and perfused with $4 \%$ paraformaldehyde in a $0.1 \mathrm{M}$ phosphate buffer (PB), $\mathrm{pH}$ 7.4. Brains were removed, postfixed overnight, and then sectioned on a vibratome $(50 \mu \mathrm{m})$. Sections were stocked in a cryoprotective solution (ethylene glycol/glycerol/PB) until proceeded for immunodetection of Fos protein.

Free-floating sections were rinsed in PBS (PB with $0.9 \% \mathrm{NaCl}$ ), and they were incubated in PBS with $0.5 \% \mathrm{H}_{2} \mathrm{O}_{2}$ for $30 \mathrm{~min}$ and then in a blocking solution containing $3 \%$ bovine serum albumin and $0.2 \%$, Triton X-100 in PBS. Sections were incubated with the rabbit polyclonal antibody anti-c-Fos (1:20,000; Ab-5 \#PC38; Oncogene Research, San Diego, CA) in a PBS-BSA-Triton X-100 solution during $24 \mathrm{~h}$ at $4^{\circ} \mathrm{C}$. After extensive washes in PBS, sections were incubated in biotinylated goat anti-rabbit IgG (1:2000; Jackson Immunoresearch, West Grove, PA) for $2 \mathrm{~h}$ at room temperature. Sections were then incubated in avidinbiotinylated horseradish peroxidase complex (Vectastain Elite kit; Vector Laboratories) for $2 \mathrm{~h}$ at room temperature. After sections were rinsed, the peroxidase reaction end product was visualized in $0.05 \mathrm{M} \mathrm{PB}$ containing diaminobenzidine tetrahydrochloride $(0.025 \%)$ and $0.03 \% \mathrm{H}_{2} \mathrm{O}_{2}$. Finally, sections were mounted on gelatin-coated glass slides, dehydrated through a graded series of ethanol, cleared in toluene, and coverslipped with Eukitt mounting medium.

For each animal, the number of Fos-immunoreactive neurons was counted bilaterally using three to four sections taken through the dorsal hippocampus [CA1-CA3 and dentate gyrus (DG)], the dorsal striatum [mediodorsal striatum (MDStr), laterodorsal (LDStr)], and the prelimbic and infralimbic parts of prefrontal cortex (PFC). The number of positive nuclei was quantified using a computerized imaging analysis system (Visiolab 2000 version 4.50; Biocom, Paris, France). Positive Fosimmunoreactive cells were expressed as the number of positive nuclei per square millimeter.

\section{Experimental design}

Experiment 1: vitamin A supplementation and $R A$ effects on hippocampal and striatal $m R N A$ expression of retinoid genes at different ages

In this experiment, quantitative real-time RT-PCR analyses were performed on hippocampal and striatal samples to study the effects of nutritional vitamin A supplementation, RA treatment, and their combination on mRNA expressions of selected genes in memory-related brain areas during aging. There were 12 groups of mice (two diets $\times$ two treatments $\times$ three ages). The final number of subjects in each group was as follows: control + vehicle young, $n=9$; control + RA young, $n=10$; enriched + vehicle young, $n=8$; enriched + RA young, $n=10$; control + vehicle middle-aged, $n=10$; control + RA middle-aged, $n=7$; enriched + vehicle middle-aged, $n=9$; enriched + RA middle-aged, $n=$ 7 ; control + vehicle aged, $n=6$; control + RA aged, $n=7$; enriched + vehicle aged, $n=8$; enriched + RA aged, $n=7$.

\section{Experiments $2 A$ and $2 B$ : vitamin $A$ supplementation and $R A$} effects on STWM at different ages

Given the vitamin A supplementation and RA beneficial effects on retinoid signaling molecular markers in aged mice (demonstrated by experiment 1), the following experiments were performed to study the potential memory effects of the same nutritional and pharmacological treatments in the radial-maze STWM task.

Experiment 2A examined the effects of nutritional vitamin A supple- 
Table 1. RT-PCR data for RAR $\beta$ and $R X R \beta / \gamma$ mRNAs (mean \pm SEM calibrator normalized data) in the hippocampus and striatum for young (Y), middle-aged (MA), and aged (A) groups in the four experimental conditions: control + vehicle, control + RA, enriched + vehicle, and enriched + RA in experiment 1

\begin{tabular}{|c|c|c|c|}
\hline & RAR $\beta$, hippocampus & RAR $\beta$, striatum & RXR $\beta / \gamma$, hippocampus \\
\hline Young control + vehicle & $0.584(0.059)$ & $1.164(0.067)$ & $0.751(0.065)$ \\
\hline Middle-aged control + vehicle & $0.538(0.047)$ & $1.103(0.052)$ & $0.718(0.039)$ \\
\hline Aged control + vehicle & $0.495(0.040)$ & $1.112(0.077)$ & $0.628(0.070)$ \\
\hline Young enriched + vehicle & $0.595(0.041)$ & $1.129(0.068)$ & $0.780(0.064)$ \\
\hline Middle-aged enriched + vehicle & $0.656(0.074)$ & $1.087(0.049)$ & $0.719(0.065)$ \\
\hline Aged enriched + vehicle & $0.688(0.087)$ & $1.029(0.053)$ & $0.843(0.081)$ \\
\hline Young control + RA & $0.608(0.033)$ & $1.220(0.082)$ & $0.690(0.043)$ \\
\hline Middle-aged control + RA & $0.593(0.034)$ & $1.146(0.090)$ & $0.744(0.100)$ \\
\hline Aged control + RA & $0.608(0.052)$ & $1.104(0.122)$ & $0.778(0.116)$ \\
\hline Young enriched + RA & $0.576(0.032)$ & $1.200(0.062)$ & $0.798(0.055)$ \\
\hline Middle-aged enriched + RA & $0.571(0.058)$ & $1.108(0.037)$ & $0.651(0.041)$ \\
\hline Aged enriched + RA & $0.571(0.062)$ & $1.074(0.080)$ & $0.866(0.195)$ \\
\hline
\end{tabular}

mentation on STWM in young, middle-aged, and aged mice. Six groups of mice were tested in parallel in the STWM paradigm. After two replications, the final number of mice in each group was as follows: control young, $n=10$; enriched young, $n=10$; control middle-aged, $n=13$; enriched middle-aged, $n=13$; control-aged, $n=9$; enriched-aged, $n=$ 8.

Experiment 2B compared the effects of vitamin A supplementation, RA treatment, and their combination on STWM in middle-aged and aged mice. After three replications, the final number of subjects in each group was as follows: control + vehicle middle-aged, $n=5$; control + RA middle-aged, $n=8$; enriched + vehicle middle-aged, $n=5$; enriched + RA middle-aged, $n=8$; control + vehicle aged, $n=4$; control + RA aged, $n=7$; enriched + vehicle aged, $n=4$; enriched + RA aged, $n=8$.

\section{Experiments $3 A$ and $3 B$ : vitamin A supplementation effects on} aging-related LTDM deficit

Given the vitamin A supplementation and RA beneficial effects on STWM in aged mice (demonstrated in experiments $2 \mathrm{~A}$ and $2 \mathrm{~B}$ ), the following experiments examined vitamin A supplementation effect on LTDM by using the two-stage discrimination learning paradigm in which the beneficial RA effect against the aging-related deficit was demonstrated previously (Etchamendy et al., 2001). In this paradigm, the age-related impairment in flexible memory expression (as revealed by stage 2 testing) was shown recently to derive from a primary STWM decline during (stage 1) learning; this STWM deficit was associated with an hypoactivity of the (hippocampo-prefrontal) declarative memory system and was believed to hinder relational encoding of individual arm experiences made during learning, into a unified LTDM representation (Mingaud et al., 2007) (our unpublished data).

Experiment 3A examined the patterns of (stage 1) learning-induced brain activation in declarative memory system (hippocampus, prefrontal cortex) and procedural memory system (striatum) using a Fos neuroimaging approach in control young, control aged, and enriched aged groups. Half of the mice were killed $90 \mathrm{~min}$ after the beginning of third session of go/no-go training for immunodetection of Fos protein. These mice were referred to as radial arm maze (RAM) groups and compared with animals that were submitted to repeated locomotor activity on a treadmill (TM) and killed after such training. TM training is used as control condition for measuring neuronal activity unrelated to memory processes engaged by RAM tasks (cf. Touzani et al., 2003; Mingaud et al., 2007). Both apparatus were located in the same room, and each TM mouse was run in parallel with an RAM mouse. The final number of animals in each group was as follows: RAM control young, $n=6$; TM control young, $n=4$; RAM control aged, $n=6$; TM control aged, $n=5$; RAM enriched aged, $n=7$; TM enriched aged, $n=5$.

Experiment $3 \mathrm{~B}$ examined the effect of vitamin A supplementation on the age-related deficit in (stage 2) LTDM expression. Control young $(n=$ $9)$, control aged $(n=6)$, and enriched aged $(n=7)$ mice were trained in the two-stages of our radial-maze discrimination learning paradigm.
Experiment 4: retinoid receptor knock-out effects on LTDM This experiment examined LTDM in adult RAR $\beta / R X R \gamma$ double knockout mice that were shown previously to display a working memory deficit (Wietrzych et al., 2005). Knock-out mice $(n=9)$ and their controls $(n=$ 8 ) were trained in the two-stage discrimination paradigm.

\section{Statistical analysis}

Data were submitted to ANOVAs. When appropriate, post hoc comparisons were performed using Fisher's PLSD tests.

\section{Results}

Experiment 1: vitamin A supplementation and RA effects on selected retinoid gene $\mathrm{mRNA}$ expression in the hippocampus and striatum at different ages

RT-PCR analysis of RAR $\beta$ and RXR $\beta / \gamma$ expression was presented in Table 1.

\section{The specific receptor for $R A$ signaling, $R A R \beta$}

When administered alone, the enriched diet or, to a lesser extent, short-term RA tended to enhance the hippocampal expression of RAR $\beta m R N A s$ in middle-aged and aged mice, this effect being larger in the aged mice. However, the coadministration of enriched diet and RA did not lead to further enhancement of RAR $\beta m R N A$ expression. In fact, the treatment with RA tended to reduce $\operatorname{RAR} \beta m R N A$ levels in the enriched groups.

These observations were supported by a three-way ANOVA of hippocampal $m R N A s$ with the factors age (young, middle-aged, and aged), diet (control and enriched), and treatment (vehicle and RA). This analysis revealed a significant diet $\times$ treatment interaction $\left(F_{(1,86)}=4,3 ; p=0.04\right)$. Analyses restricted to each treatment condition showed that the diet effect was significant in the vehicle condition $\left(F_{(1,46)}=4 ; p=0.05\right)$ but not RA condition $(p>0.14)$. Whereas analyses restricted to each diet condition showed that the treatment effect approached statistical significance in the enriched $\left(F_{(1,44)}=3.4 ; p=0.07\right)$ but not control condition $\left(F_{(1,45)}=2.6 ; p=0.11\right)$. Finally, analysis restricted to each age showed that diet $\times$ treatment approached statistical significance in the aged groups $(p=0.06)$ but not in the other groups of age (all $p$ values $>0.38$ ). Namely, compared with control + vehicle mice, aged mice fed with the enriched diet or treated with RA displayed, respectively, $+39 \%(p=0.057, \mathrm{NS})$ and $+30 \%$ ( $p=0.11$, NS) increase of $\operatorname{RAR} \beta m R N A$ expression, whereas the combination of enriched diet and RA led to only $+15 \%$ increase.

When considering striatal levels of RAR $\beta$ mRNA expression, 
no between-group difference was observed. This observation was confirmed by the statistical analysis: age, $p>0.14$; diet, $p>0.37$; treatment, $p>0.36$ for main group effects and $F<1$ for all interactions analyzed by three-way ANOVA.

\section{Concerning a nuclear receptor unspecific for $R A$} signaling, $R X R \beta / \gamma$

Slight between-group variations of its hippocampal $m R N A$ expression were observed only in aged samples. $\operatorname{RXR} \beta / \gamma m R N A$ levels in control + vehicle aged mice seemed to be lower than in the other aged groups (control + RA, enriched + vehicle, or enriched + RA). However, neither the three-way ANOVA nor analysis restricted to one-factor condition revealed any statistically significant effect of age, diet, or treatment (all $p$ values $>0.13)$.

A functional indicator of the retinoid receptor signaling: expression of a synaptic plasticity-related gene, GAP-43

Hippocampal levels of GAP43 $m R N A s$ for the different groups of age, diet, and treatment are shown in Figure $3 A$. When considering only animals treated with vehicle, it clearly appears that aging was associated with a progressive decline in hippocampal GAP43 $m R N A$ levels in the control condition of feeding, whereas the same biochemical measure regularly increased between young adulthood, middle age, and old age in mice fed with the vitamin A-enriched diet. In fact, the enriched diet tended to reduce GAP43 $m R N A$ expression in young adults, whereas it obviously increased this expression in aged mice. Concerning the treatment with RA alone, it can be seen that this treatment had no effect in young or middle-aged groups but tended to enhance hippocampal $m R N A$ expression of GAP43 in aged mice, although with less efficiency than the enriched diet (high between-subject variability).

These observations were supported by a three-way ANOVA of hippocampal GAP43 $m R N A$ levels, which revealed that only the age $\times$ diet interaction approached statistical significance $\left(F_{(2,86)}\right.$ $=3,04 ; p=0.053$; for all other factors and interactions, $p>0.27$ ). Analyses restricted to each treatment condition showed that the age $\times$ diet interaction was significant in vehicle $(p=0.02)$ but not RA condition $(F<1)$. This interaction in vehicle groups was linked to the fact that GAP43 $m R N A$ expression was reduced by the enriched diet in young adults $(-20 \%$, NS) but was increased by $59 \%$ in aged mice $(p=0.014)$. Analyses restricted to each diet and treatment condition showed that there was a significant effect of age only in the control + vehicle condition $(p=0.04)$ in which, compared with the adult group, the middle-aged and aged groups displayed, respectively, $-20 \%$ (NS) and $-34.2 \%$ ( $p=$ 0.012 ) reduction of GAP43 expression. This age-related decrease was not seen in groups fed with the enriched diet or treated with RA.

When considering the striatal levels of GAP43 mRNAs (Fig. $3 B$ ), no significant between-group variation was observed (age, $p>0.11$; diet, $F<1$; treatment, $p>0.21$; all interactions, $F<1$ ).

Taken as a whole, real-time RT-PCR data of experiment 1 indicated the following. (1) In the control feeding condition, aging was associated with a reduction of retinoid signaling in the hippocampus but not in the striatum. Although aging-related variations were moderate concerning retinoid receptor expression, a functional alteration of hippocampal retinoid receptor signaling was clearly evidenced in aged control mice by hypoexpression of a retinoid receptor transcriptional target gene, GAP43. (2) Lifelong feeding with the vitamin A-enriched diet prevented this aging-related hypofunction of retinoid signaling pathway in the hippocampus without affecting retinoid gene ex-
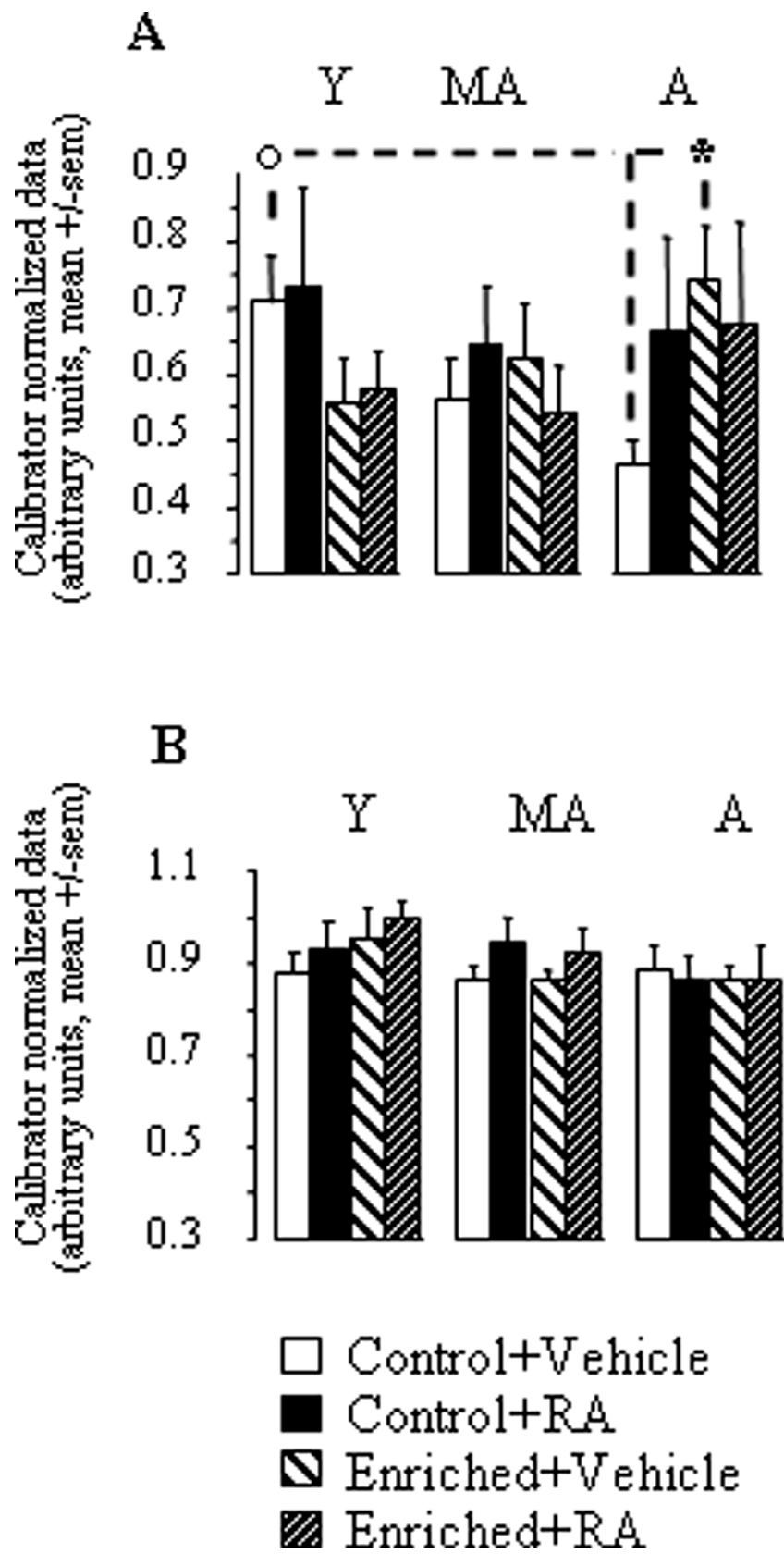

Figure 3. $\quad \boldsymbol{A}, \boldsymbol{B}, \mathrm{GAP} 43 \mathrm{mRNA}$ expression in the hippocampus $(\boldsymbol{A})$ and striatum $(\boldsymbol{B})$ for young $(Y)$, middle-aged (MA), and aged (A) groups in the four experimental conditions: control + vehicle, control $+R A$, enriched + vehicle, and enriched + RA in experiment 1. Comparison of two age groups in the same experimental condition, ${ }^{\circ} p<0.05$. Comparison of two groups of the same age, ${ }^{*} p<0.05$.

pression in the striatum. (3) Systemic administration of RA to aged mice produced the same pattern of molecular effects as vitamin A supplementation, although with less efficacy and in a manner that was not additive to the enriched-diet effect.

\section{Experiment 2: vitamin A supplementation and RA effects on} STWM at different ages

Experiment 2A: vitamin A supplementation effects in young, middle-aged, and aged mice

Evolution of performance over training. We can observe in Figure $4 A$ that the performance progression over the six blocks of training sessions was clearly dependent on the group considered. 

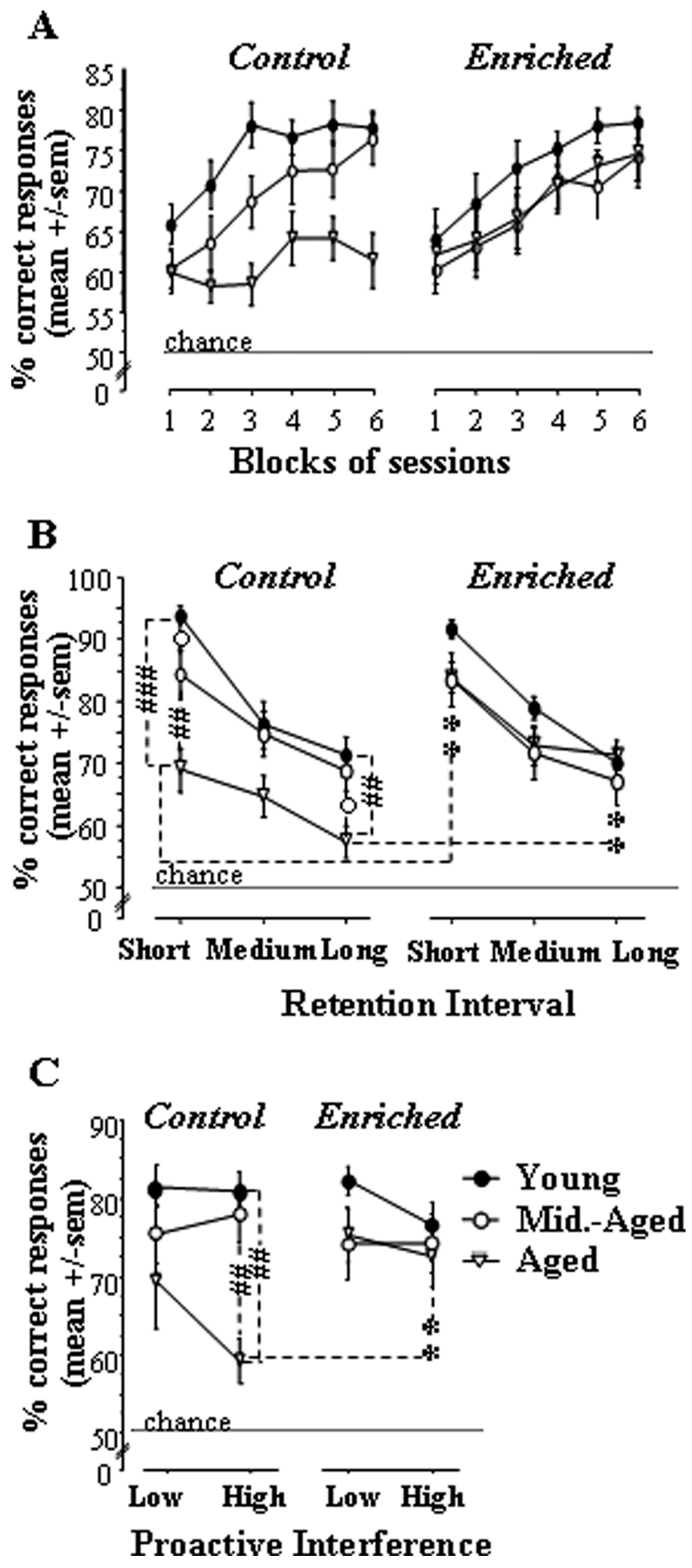

Figure 4. Performance in the STWM task for each age group in control and vitamin A-enriched conditions in experiment 2A. $\boldsymbol{A}-\boldsymbol{C}$, Performance across blocks of sessions $(\boldsymbol{A})$, as a function of retention interval (short, medium, and long; $\boldsymbol{B}$ ) and proactive interference levels (low and high; (C). Comparison of two age groups in the same nutritional condition, ${ }^{\#} p<0.05$, ${ }^{\# \#} p<0.01,{ }^{\# \# \#} p<0.001$. Comparison of two diet groups of the same age, ${ }^{* *} p<0.01$.

In control groups (Fig. $4 A$, left), a clear age-related difference appeared. In young and middle-aged groups, response accuracy improved over the first three blocks and reached approximately the same asymptotic level of performance ( $74-78 \%$ correct). In contrast, performance of the aged control group did not improve and remained below adult and middle-aged ones over the entire course of training. These findings were confirmed by an ANOVA on repeated measures with block as an internal factor and age as a between factor. This analysis yielded significant effects of age $\left(F_{(2,29)}=6.96 ; p=0.003\right.$; post hoc, aged vs young, $p=0.001$; aged vs middle aged, $p=0.032)$, block $\left(F_{(5,145)}=13.42 ; p<0.0001\right)$, and their interaction $\left(F_{(10,145)}=2.43 ; p=0.01\right)$. Analyses restricted to each age showed that the block effect was highly significant in the young and middle-aged groups $(p<0.0001$ in each case) but not in the aged group $(p=0.09)$.

A clearly different picture emerged in the enriched-diet condition (Fig. $4 A$, right), wherein the aged group was indistinguishable from the middle-aged one; these two groups performed just slightly below the adult group and reached $\sim 75 \%$ correct responses in the final session blocks. An ANOVA conducted on these data revealed a significant effect of block $\left(F_{(5,140)}=20.13\right.$; $p<0.0001)$, with no effect of age $(p>0.29)$ and interaction $(F<$ $1)$, because each group improved response accuracy as training progressed (block, $p \leq 0.012$ in each case).

There was a significant between-diet difference on overall performance (mean over the entire training period) in aged groups (diet, $\left.F_{(1,15)}=5.93 ; p=0.028\right)$ but not adult or middle-aged ones (diet, $F<1$ in both cases).

These results showed that the vitamin A-enriched diet prevented the occurrence of a performance deficit in aged mice without affecting the performance of younger (young and middleaged) subjects. To assess the mnemonic specificity of both the deleterious effect of aging and the preventive effect of vitamin A supplementation, additional detailed behavioral analyses were performed.

Detailed analyses of performances at the end of training. These analyses were restricted to the final (five to six) blocks of training sessions, i.e., at a time when all groups except the control aged one reached approximately the same asymptotic level of performance

Retention interval. As explained in Materials and Methods, retention interval for one specific arm visit depended on the number of intervening trials (with other pairs) between the acquisition trial and the test trial for this specific arm visit. Performances were averaged by trials of retention interval levels: short (zero intervening trial), medium (one to two intervening trials), and long (three to four intervening trials).

Expected effects of retention interval on performances were confirmed by the results: as depicted in Figure $4 B$, regardless of the diet and age condition, response accuracy clearly decreased with increasing retention intervals. Nevertheless, the magnitude of between-age differences in control groups and between-diet difference in the aged group was not equivalent across the different retention intervals. In fact, such differences were larger for the short retention interval than for the longer ones.

These observations were confirmed by an ANOVA that included the between-subject factors age and diet together with the within-subject factor retention interval (three levels: short, medium, and long). This analysis revealed significant effects of retention interval $\left(F_{(2,114)}=84.86 ; p<0.0001\right)$, retention interval $\times$ age $\left(F_{(4,114)}=2.45 ; p=0.049\right)$, and age $\times \operatorname{diet}\left(F_{(2,57)}=\right.$ 3.36; $p=0.042)$.

Analyses restricted to each diet and interval condition showed that the effect of age in control groups reached statistical significance for both short $\left(F_{(2,29)}=12.2 ; p=0.0001\right.$; post hoc, young vs middle-aged, $p=0.049$; young vs aged, $p<0.0001$; middle-aged vs aged, $p=0.003$ ) and long (age, $F_{(2,29)}=5.7 ; p=0.008$; post $h o c$, young vs middle-aged, $p>0.5$; young vs aged, $p=0.004$; middle-aged vs aged, $p=0.01$ ) retention intervals but not me- 
dium retention intervals (age, $p>0.08$ ). In contrast, no betweenage difference was observed in enriched-diet groups (age, $p>$ 0.18 , whichever the retention interval considered).

Analyses restricted to each age and interval condition showed that the effect of diet reached statistical significance in the aged groups only and for short $\left(F_{(1,15)}=12.3 ; p=0.003\right)$ and long $\left(F_{(1,15)}\right.$ $=14.8 ; p=0.003)$ but not medium $(p>0.08)$ retention intervals.

In conclusion, these detailed analyses showed that, regardless of age and feeding conditions, the performance was modulated in the expected direction by mnemonic demand: the longer the retention interval, the poorer the performance. However, the surprising observation that the age- (or diet-) related differences were maximal when the difficulty (retention interval) was minimal suggested that another factor produced variations in task demand (and performance) between trials. As demonstrated by the following analyses, the level of proactive interference also modulated choice accuracy.

Proactive interference was potentially produced by reusing of the same items (pairs of arms) across trials. In any $n$ trial, the probability of effective proactive interference was dependent on the distance separating the acquisition trial $(n-1)$ from the preceding trial with the same pair $(n-2)$ : the shorter the distance, the higher the probability of effective proactive interference. To analyze such potential effects, we distinguished two proactive interference levels: low PI (three to four trials with other pairs interposed between $n-2$ and $n$-1) and high PI (zero to one trial interposed between $n-2$ and $n-1$ ).

As can be seen in Figure $4 C$, regardless of the diet condition, young and aged mice displayed better accuracy in low PI than high PI trials. This modulation of performance by proactive interference level was particularly observed in control aged mice. Hence, in high PI trials, aged mice fed with the control diet were impaired relative to adult and middle-aged groups of the same nutritional condition ( -28.4 and $-25.6 \%$, respectively), as well as to aged mice fed with the enriched diet $(-21.6 \%)$. In contrast, in low PI trials, the control aged group performed at only -12.2 and $-4.6 \%$ of performances of younger control adult and middle-aged groups and at approximately the same level as enriched aged mice $(-4 \%)$.

These observations were supported by an ANOVA, including the between-subject factors age and diet together with the withinsubject factor proactive interference. This analysis revealed a significant effect of proactive interference $\left(F_{(1,57)}=7.5 ; p=0.008\right)$ and proactive interference $\times$ age interaction $\left(F_{(2,57)}=5.2 ; p=\right.$ $0.008)$. ANOVAs restricted to each condition of proactive interference revealed significant effects of age $\left(F_{(2,57)}=5.54 ; p=\right.$ $0.006)$ and age $\times \operatorname{diet}\left(F_{(2,57)}=4.4 ; p=0.017\right)$ in high PI trials but not in low PI trials (age, $p>0.08$; diet and age $\times$ diet, $F<1$ ).

These findings demonstrated that (1) control aged mice were more sensitive to proactive interference than their younger controls, and (2) vitamin A supplementation was protective against this aging-related enhancement of susceptibility to proactive interference.

In conclusion, results of experiment $2 \mathrm{~A}$ showed the following. First, in conditions of control diet, aging was associated with a progressive decline of performance. This age-related impairment appeared to be memory specific because it was observed when proactive interference level was high only. Second, the vitamin A-enriched diet was protective against this STWM decline because no age-related difference was observed in enriched-diet groups. The diet effect was specific of the aging-related memory decline because (1) no effect of the diet was noticeable in adult or middle-aged animals, and (2) the beneficial effect observed in aged mice was not global but seen in high PI trials only.
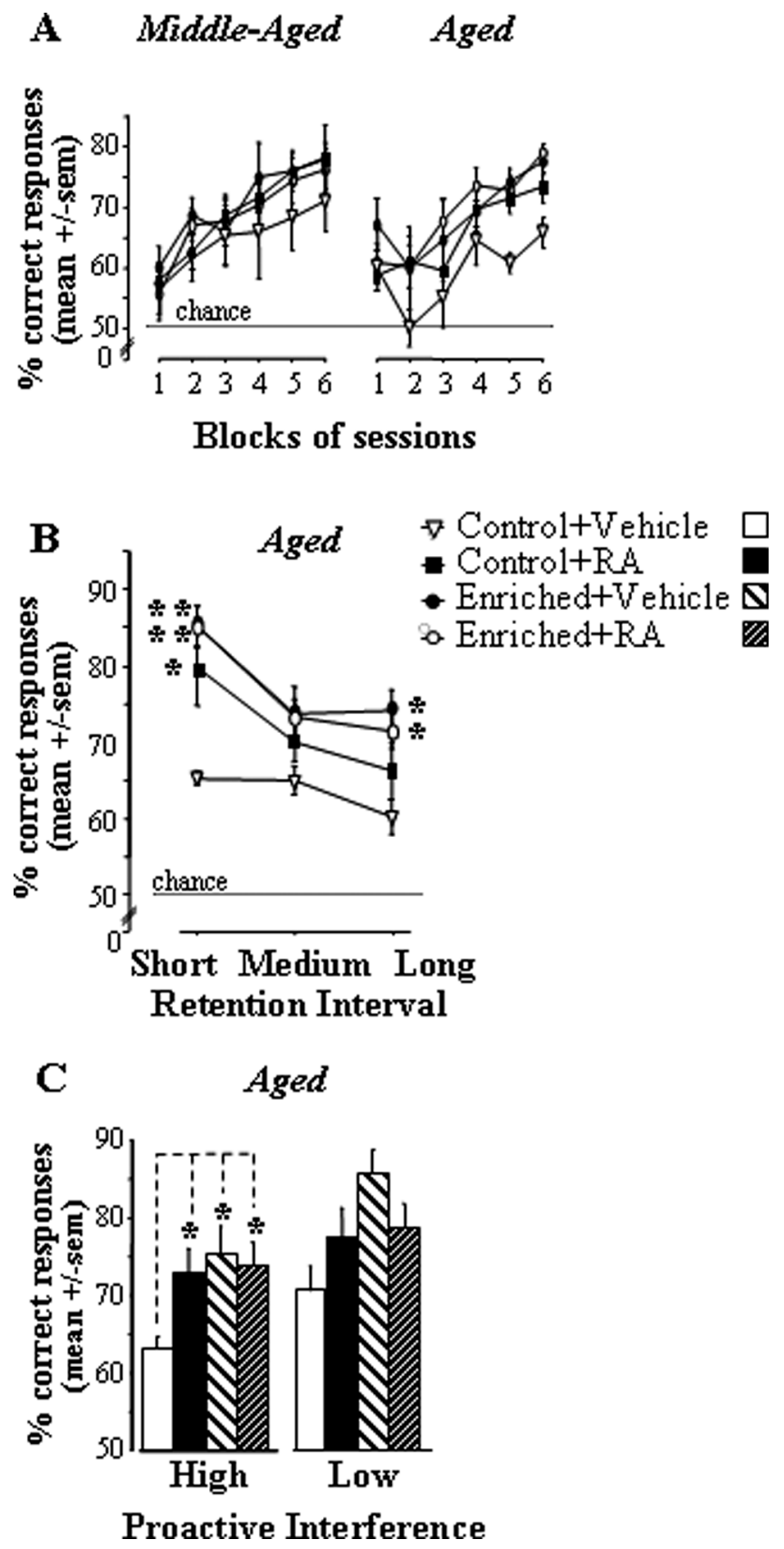

Figure 5. Performance in the STWM task for aged and middle-aged groups treated with RA or vehicle in control feeding and vitamin A-enriched diet conditions in experiment 2B. A-C, Performance across blocks of sessions $(\boldsymbol{A})$, as a function of retention interval (short, medium, and long; $\boldsymbol{B}$ ) and proactive interference levels (low and high; $\boldsymbol{C}$. Comparison of two diet groups of the same age, ${ }^{*} p<0.05,{ }^{* *} p<0.01,{ }^{* * *} p<0.001$.

Experiment 2B: comparative effects of vitamin A supplementation and $R A$ in middle-aged and aged mice

Progression of STWM performances over training. It can be seen in Figure $5 A$ that performance levels increased with repeated training, but this progression was dependent on the group considered. Indeed, in each condition of age, the control + vehicle group did not reach the same level of choice accuracy as the other three groups (i.e., control + RA, enriched + vehicle, and enriched + $\mathrm{RA})$ in the final two blocks of sessions.

An ANOVA including the between-subject factors age (two levels: middle-aged and aged), diet (two levels: control and enriched), and treatment (two levels: vehicle and RA), and the 
within-subject factor block (six blocks of three sessions each) revealed significant effects of block $\left(F_{(5,205)}=43.71 ; p<0.0001\right)$ and diet $\left(F_{(1,41)}=4.57 ; p=0.039\right)$. When the analysis was restricted to the final two blocks, a significant diet $\times$ treatment interaction emerged $\left(F_{(1,41)}=4.16 ; p=0.048\right)$ because the beneficial effect of treatment was significant in control $(p=0.019)$ but not enriched groups $(\mathrm{F}<1)$. These effects were mainly attributable to the aged groups because no significant difference was observed among the middle-aged groups (all $p$ values $>0.17$ ) whereas, in the aged, the control + vehicle group displayed significantly lower performance than each other group (all $p$ values $<0.01$ ). It can also be seen that performance levels were identical between the two aged groups fed with the enriched diet (i.e., enriched diet alone vs enriched diet + RA), whereas the mean performance of control + RA mice was slightly below.

Detailed analyses of final performance in the aged groups. Detailed analyses of performances measured in the two final blocks of sessions were limited to the aged groups because no betweengroup difference was observed in middle-aged animals.

Retention interval. In line with observations made in experiment 2A, we observed (Fig. $5 B$ ) that, whichever the group considered, performance diminished as retention intervals increased (retention interval, $F_{(2,38)}=19.2 ; p<0.0001$ ). Furthermore, the difference between the control + vehicle group and the three other ones was larger for the short retention interval than for the medium and long intervals (group effect for short interval, $F_{(3,19)}$ $=4.7, p=0.012$; post hoc, control + vehicle group significantly different from each of the other groups; group effect for medium interval, $p>0.15$; for long interval, $p=0.055)$.

Proactive interference. Also confirming observations made in experiment $2 \mathrm{~A}$, the analysis of proactive interference effects (Fig. $5 C$ ) showed that the deficit of control + vehicle aged mice relative to each other aged group was statistically significant in high PI trials (group, $F_{(3,19)}=3.4 ; p=0.04 ;$ post hoc, control + vehicle vs each other group, $p<0.03$ ) but not in low PI trials (group, $p>$ 0.31 ).

In conclusion, findings from experiment $2 \mathrm{~B}$ confirmed and extended the conclusions of experiment $2 \mathrm{~A}$ in showing that (1) the STWM paradigm evidenced specific memory deficits in aged mice, (2) vitamin A supplementation selectively prevented such aging-related STWM decline because it did not significantly change performance of middle-aged mice nor those of aged mice in low PI trials, (3) short-term pharmacological treatment with RA produced the same pattern of beneficial effects although with slightly less efficiency, and (4) vitamin A supplementation memory benefits were not further increased by the coadministration of RA, suggesting that the nutritional supplementation did maintain an optimum level of retinoid signaling function. This conclusion is in line with molecular findings of experiment 1 .

\section{Experiment 3: vitamin A supplementation effects on aging- related LTDM deficiency}

Experiment 3A: vitamin A supplementation effect on age-related defect of the recruitment of hippocampal and prefrontal areas by LTDM encoding, as revealed by Fos immunochemistry

Control young, control aged, and enriched aged groups of mice were killed for immunohistochemical detection of Fos protein after (the third) go/no-go discrimination learning session to map encoding-related activity in brain areas known to be involved in long-term declarative (dorsal hippocampus and prefrontal cortex) and procedural (dorsal striatum) memory systems. Quantitative data are presented in Figure $6 A-C$.

In young controls, it can be seen that, compared with TM
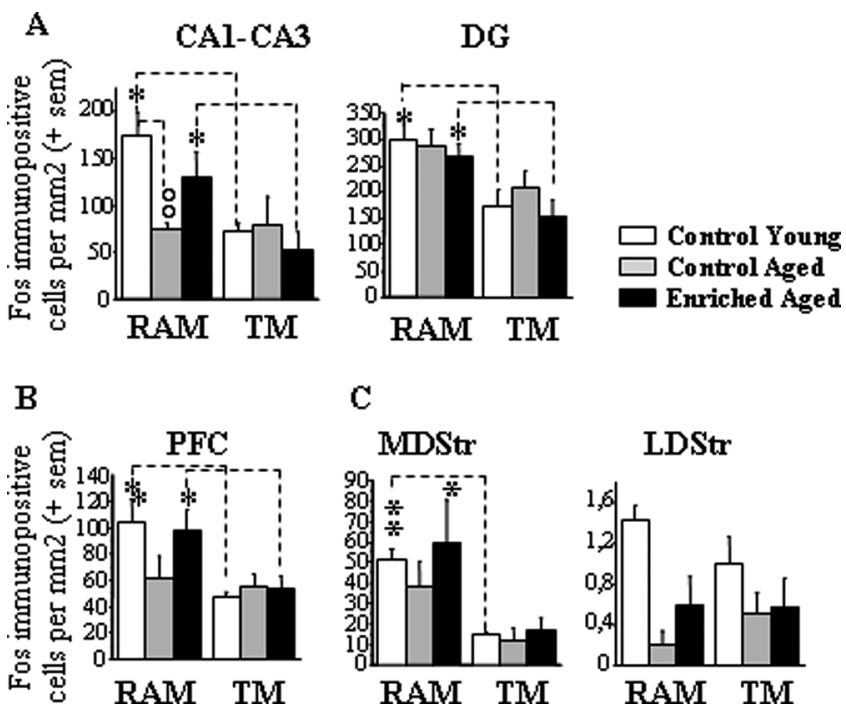

Figure 6. Quantitative measurements of Fos protein for young and aged groups in control and vitamin A-enriched diet conditions in experiment 3A. A-C, Results are expressed as mean number of Fos-immunopositive cells per square millimeter ( \pm SEM) in the hippocampus (CA1, $(A 3$, and DG; $\boldsymbol{A}), \operatorname{PFC}(\boldsymbol{B})$, and dorsal striatum (lateral and medial parts; $\boldsymbol{C}$. Comparison of two age groups of the same behavioral condition, ${ }^{\circ 0} p<0.01$. Comparison between RAM and TM groups of the same age, ${ }^{*} p<0.05,{ }^{* *} p<0.001$.

condition, RAM training induced significant increases in Fos protein levels measured in the dorsal hippocampus (CA1-CA3, $+133 \%, p=0.014$; DG, $+75 \%, p=0.05)$, PFC $(+110 \%, p=$ $0.035)$, and MDStr $(+237 \%, p=0.001)$ but not LDStr. In control aged mice, RAM-induced activation was only slightly attenuated in the DG $(+38,4 \%, p=0.137)$ and MDStr $(+221 \%, p=0.09)$ but totally absent in CA1-CA3 $(-1.3 \%, \mathrm{~F}<1)$ and PFC $(+20 \%$, $F<1)$. This deleterious aging effect on learning-induced activation of hippocampal and prefrontal areas was not observed in aged mice fed with the enriched diet (CA1-CA3, $+150 \%, p=$ 0.049 ; DG, $+73.3 \%, p=0.018$; PFC, $+77 \%, p=0.048)$. In the MDStr, however, the learning-induced activation failed to reach statistical significance in the enriched-aged group $(+248 \% ; p=$ $0.123)$. In this area, the amplitude of the task-related activation was similar to the one seen in control aged mice and control young mice. These findings were supported by two-way ANOVAs with the between-subject factors group (control adult, control aged, and enriched aged) and behavior (RAM vs TM). These analyses revealed significant effect of behavior for CA1-CA3 $\left(F_{(1,27)}=10.63 ; p=0.003\right), \mathrm{DG}\left(F_{(1,27)}=15.34 ; p=0.0006\right)$, $\operatorname{PFC}\left(F_{(1,27)}=8.85 ; p=0.006\right)$, and $\operatorname{MDStr}\left(F_{(1,27)}=10.77 ; p=\right.$ $0.003)$ and a significant group $\times$ behavior interaction for CA1CA3 only $\left(F_{(2,27)}=3.38 ; p=0.049\right)$. This interaction resulted from the fact that the group effect was significant in the RAM condition $\left(F_{(2,16)}=5.77 ; p=0.014\right.$; post hoc, control young vs control aged, $p=0.004$; control aged vs enriched aged, $p=0.08$ ) but not TM condition $(F<1)$. Indeed, it can be seen that, compared with control adult and enriched aged levels, the densities of Fos-positive cells within CA1-CA3 were reduced in control aged mice submitted to RAM training but was comparable between the three groups submitted to TM training.

The sole area for which the analysis revealed no significant effect of behavior $(F<1)$ and a main effect of group $\left(F_{(2,27)}=\right.$ 9.23; $p=0.0009$; post hoc, control young vs control aged, $p=$ 0.0001 ; control young vs enriched aged, $p=0.003$ ) was LDStr, in which, regardless of the behavioral condition, Fos expression was lower in the two aged groups. 


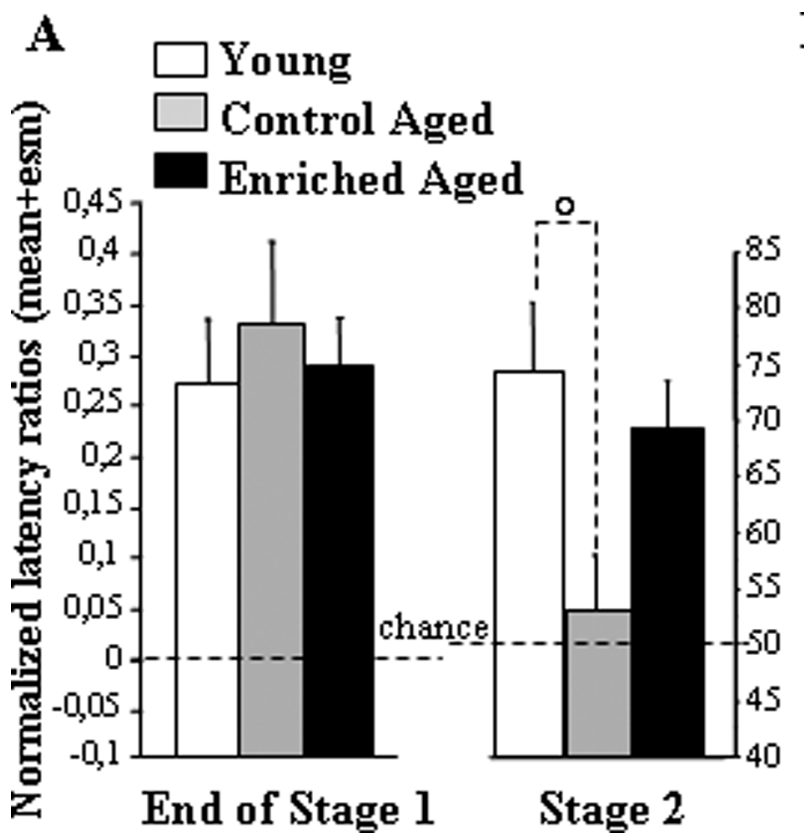

Figure 7. Performance in the LTDM paradigm for young and aged groups in the control feeding condition and an aged group in the vitamin A-enriched diet condition in experiment $3 \mathrm{~B}$. $\boldsymbol{A}$, Normalized discriminative ratio over the last two sessions of training before reaching the criterion in stage 1. All groups of mice entered significantly faster into baited arms than unbaited ones. $\boldsymbol{B}$, Mean \pm SEM percentage of correct choices over the two sessions of the twochoice tests. Comparison of young and aged control groups, ${ }^{\circ} p<0.05$.

These Fos imaging data demonstrated first that brain activity was increased by the go/no-go discrimination learning task in memory-related areas, and age-related changes in task-related activations were specific to hippocampal areas (and, to a lesser extent, prefrontal cortex), which are known to be critically involved in declarative memory. Second, vitamin A supplementation prevented this deficiency in encoding-induced declarative memory system recruitment without affecting learning-related activity in the striatum, a brain region involved in procedural learning.

Experiment 3B: vitamin A supplementation effect on the agerelated impairment in $L T D M$

In stage 1 (successive go/no-go discrimination), the six arms were presented one by one successively. Discrimination between positive and negative arms was evidenced by the difference in the latency to enter between the two sets of arms. The three groups (control young, control aged, and enriched aged) reached the learning criterion with a similar number of training sessions (one-way ANOVA on sessions to criterion, group effect, $F_{(2,19)}=$ $1.4 ; p=0.27)$. In the final two sessions, significant between-arm discrimination was reflected in over chance discriminative ratio for each group (Fig. 7B) (one-way ANOVA, group effect, $F<1$; mean discriminative ratio vs chance, $p<0.035$ for each group).

These findings supported the conclusion that the three groups of mice similarly learned the initial go/no-go discrimination task. Neither the age nor the feeding condition in aged mice affected discriminative performance at this stage.

In stage 2 (simultaneous two-choice discrimination), the arms were presented by pairs (Fig. $7 B$ ). When faced with a choice between two familiar arms that were always experienced separately during initial learning, control aged mice behaved as if they were naive. As opposed to control young mice, they failed to choose the positive arm more often than the negative one. This

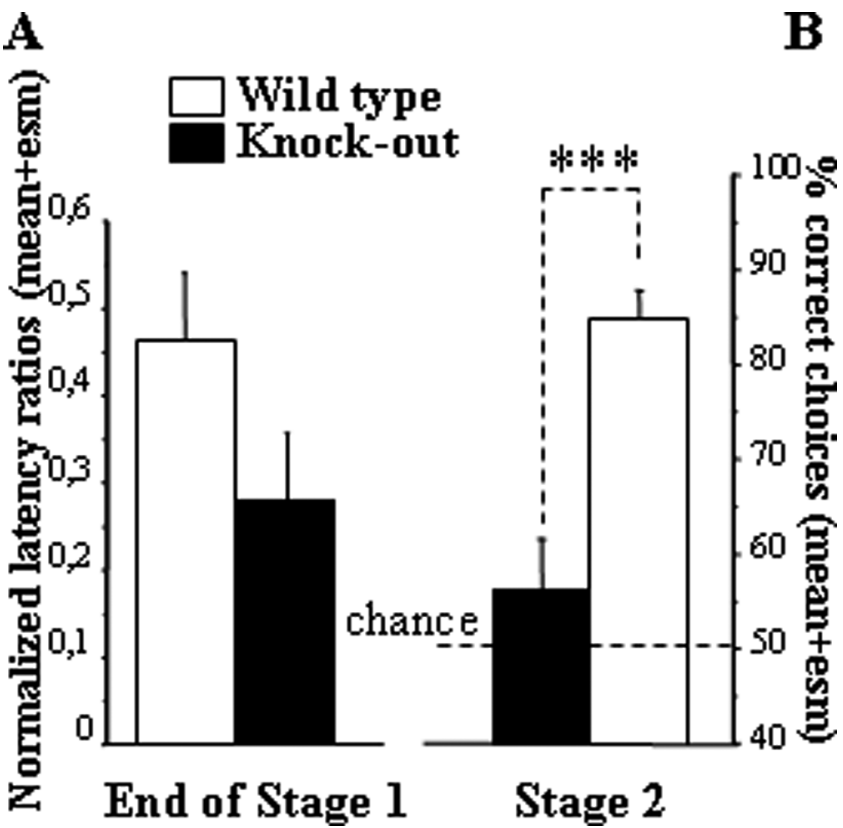

Figure 8. Performances in the LTDM paradigm for wild-type and knock-out (RAR $\beta / \operatorname{RXR} \gamma)$ groups in experiment 4. $\boldsymbol{A}$, Normalized discriminative ratio over the last two sessions of training before reaching the criterion in stage 1 . All groups of mice entered significantly faster into baited arms than unbaited ones. $\boldsymbol{B}$, Mean \pm SEM percentage of correct choices over the two sessions of the two-choice tests. Comparison of wild-type and knock-out groups, ${ }^{* * *} p<0.001$.

two-choice deficit was not observed in enriched aged mice; they displayed over-chance performance and performed at approximately the same level of choice accuracy as young mice. These findings were confirmed by a one-way ANOVA of percentage correct choices, which revealed a significant group effect $\left(F_{(2,19)}\right.$ $=3.63 ; p=0.046$; post hoc, control young vs control aged, $p=$ 0.016 ; control young vs enriched aged, $p=0.52$; enriched aged vs control aged, $p=0.07$ ).

In conclusion, experiment $3 \mathrm{~B}$ demonstrated that the selective impairment in long-term memory flexibility (LTDM) observed in control aged mice was alleviated by the vitamin A-enriched diet. Altogether, molecular and behavioral findings of experiment 3 showed that vitamin A supplementation was preventive against aging-related deficiency in hippocampo-prefrontal encoding processes and associated LTDM impairment.

\section{Experiment 4: LTDM in adult RAR $\beta / R X R \gamma$ double} knock-out mice

In stage 1 (successive go/no-go discrimination learning), all mice acquired the task after a similar number of training sessions (oneway ANOVA on sessions to criterion, group effect, $F_{(1,14)}=1.13$; $p=0.31)$. In the final sessions, the levels of between-arm discrimination reflected in the mean discriminative ratio were not different between the two groups (Fig. $8 A$ ) (group effect, $F_{(1,14)}=3.02$; $p=0.10)$.

In stage 2 (simultaneous two-choice discrimination test), the animals were challenged with novel arm presentations testing the flexibility of their acquired knowledge about individual arm valence. In this two-choice discrimination test, a clear deficit was observed in knock-out mice (Fig. $8 \mathrm{~B}$ ); their choice performance was close to chance level. These findings were confirmed by oneway ANOVA of percentage correct choices, which yielded a significant group effect $\left(F_{(1,14)}=23.37 ; p=0.0003\right)$. 


\section{Discussion}

The present series of experiments in mice were aimed at further assessing the hypothesis that compromised retinoid signaling attributable to hypoexpression of retinoid receptors contributes to hippocampal dysfunction and associated memory impairment occurring during senescence. Converging molecular and behavioral evidence provided by nutritional, pharmacological, and knock-out manipulations of retinoid signaling pathway support our hypothesis. In experiment 1, RT-PCR analyses of retinoid gene $m R N A$ expressions in control and vitamin $\mathrm{A}$-enriched mice of different ages showed that the lifelong nutritional supplementation prevented aging-related decrease in hippocampal (but not striatal) (Fig. $3 A, B$ ) expression of GAP43, a plasticity-related retinoid receptor target gene. Furthermore, short-term RA administration to aged mice produced similar (although less marked) molecular effects that were occluded by the enriched diet, hence suggesting that vitamin A supplementation maintained optimal activation of retinoid nuclear receptors in aged mice. In experiment 2, both vitamin A supplementation (Fig. 4C) and RA treatment (Fig. $5 C$ ) were shown to alleviate the age-related performance deficit in organizational demanding trials (high proactive interference level) of the STWM radial-maze task. In the following experiments, we used a two-stage radial-maze discrimination paradigm in which RA was shown previously to alleviate the selective aging-related impairment in LTDM flexibility (Etchamendy et al., 2001). Here, the beneficial effects of vitamin A supplementation in aging were demonstrated by experiment 3 . First, Fos immunohistochemistry revealed that the enriched diet counteracted aging-related defect in (stage 1) learning-induced hippocampal (and to a lesser extent prefrontal) activation, without affecting striatal activity (Fig. $6 A-C$ ). Second, this positive effect on encoding-related activity was associated with an alleviation of the age-related deficit in LTDM expression (stage 2 testing) (Fig. $7 B)$. In experiment 4 , using a genetic approach, we demonstrated that RAR $\beta$ and/or RXR $\gamma$ are the key retinoid receptors mediating such vitamin A signaling because concomitant null mutation of both receptors led to a behavioral deficit in LTDM similar to the one seen in control aged mice (Fig. 7B). Such findings are complementary to the critical role of retinoid receptors in normal STWM function (Wietrzych et al., 2005).

The coherence of present findings suggests the conclusion that hippocampal retinoid receptor hyposignaling contributes to aging-related deterioration in organizational information processes that normally protect STWM against interference and enable LTDM formation. Furthermore, this study demonstrated for the first time that nutritional vitamin A supplementation can be a successful strategy in preventing aging-related decline in mnemonic function.

\section{Vitamin A supplementation prevents aging-related retinoid signaling hypoexpression in the hippocampus}

Retinoid signaling hypoactivity was evidenced in aged hippocampi (but not striatal samples) by ( -20 to $30 \%$ ) reduction of RAR $\beta$ and GAP43 $m R N A$ expressions and was reversed by vitamin A supplementation or (to a lesser extent) by short-term RA. This RA effect was in agreement with our previous aging study (Etchamendy et al., 2001) wherein both behavioral and molecular RA benefits were shown to result from nuclear receptor activation because they were totally suppressed by coadministrating a specific RAR antagonist. Here, the similarity between nutritional supplementation and short-term RA effects, together with the occlusion of RA benefits by the enriched diet, suggested that the lifelong vitamin A supplementation has acted through maintaining optimal activation of retinoid nuclear receptors.

Interestingly, retinoid signaling expression in the striatum was not modified by manipulations of age, vitamin A intake, and RA administration. This observation supports the conclusion that the mature hippocampus is distinctly prominent site of RA action. This conclusion is in agreement with recent findings showing that this region is particularly rich in RA (for review, see McCaffery et al., 2006).

Our correlative approach did not enable us to establish which specific proteins were causally involved in memory effects; among the multitude of retinoid target genes, GAP43 is one protein that may contribute to these effects given its implication in synaptic and cellular plasticity (for review, see Biewenga et al., 1996; Benowitz and Routtenberg, 1997; Mosevitsky, 2005). However, our present findings indicated that normal hippocampal function requires precise adjustment of retinoid-mediated transcription control, and vitamin A nutritional intake is one factor involved in this regulation. Although retinoid signaling hypoexpression could account for aging-related hippocampal dysfunction (Brouillette and Quirion, 2007), vitamin A or RA in excess during adulthood might have disruptive effects (Crandall et al., 2004).

\section{Hippocampal retinoid signaling hypoexpression is associated with specific cognitive disturbances}

In the present experiments, retinoid signaling hypoexpression was associated with behavioral deficits observed only in trials with high proactive interference in the STWM task (aged mice) (Figs. $4 C, 5 C$ ) and in the critical test of mnemonic flexibility in the LTDM paradigm (aged and knock-out adult mice) (Figs. $7 B$, $8 B)$.

Concerning STWM, detailed performance analyses demonstrated that choice accuracy decreased with increasing retention intervals whichever the group (Figs. $4 B, 5 B$ ), but the age-related deficit was more particularly observed at short retention intervals. This unexpected deficit in low retention demanding trials might be explained by the temporal proximity of preceding trials maximizing organizational demand with regard to proactive interference. We indeed observed here that aged mice displayed enhanced sensitivity to proactive interference as previously shown in aged rats (Winocur, 1984; Dunnett et al., 1990), monkeys (Moss et al., 1988), and humans (Smith, 1979; Craik and Rabinowitz, 1985; Daigneault and Braun, 1993; Bowles and Salthouse, 2003; McCabe et al., 2005). In summary, the impairment of aged mice was not equivalent among STWM trials but was particularly observed when organizational demand was high; it is therefore likely to reflect an overloading of STWM capacity.

In the LTDM paradigm, a robust performance deficit was observed in stage 2 two-choice testing, in which aged (and adult knock-out) mice behaved as if they were naive of previous arm experiences despite the fact that they exhibited normal acquisition of (go/no-go) between-arm discrimination in stage 1 (Figs. $7 A, B, 8 A, B)$. This specific loss of mnemonic flexibility, revealed by a test situation demanding an explicit comparison between separately acquired information, has been proposed as a mouse model for the preferential declarative memory loss in senescence (Marighetto et al., 1999, 2000) and in association with hippocampal dysfunction (Etchamendy et al., 2001, 2003; Touzani et al., 2003; Mingaud et al., 2007). The deficit selectivity enables us to rule out trivial explanations (such as deterioration in motivation, perception, and locomotion) for observed changes in behavior (and concomitant brain activity, see below) in the aged mice. The 
selective two-choice deficit is interpreted as a loss in the ability to encode individual arm experiences into a relational representation sustaining mnemonic flexibility, i.e., LTDM (Cohen and Eichenbaum, 1993; Eichenbaum, 2004), with the sparing of procedural learning capabilities relying on rigid and separate memory representations (for aged monkeys, see also Rapp et al., 1996). As demonstrated recently (Mingaud et al., 2007) and further confirmed by present Fos imaging data, mnemonic inflexibility as revealed by stage 2 testing is associated with a defect in (stage 1) learning-induced activation of hippocampal and prefrontal areas, known for subserving declarative memory.

Aging-related deficits in STWM organization and LTDM were both alleviated by the vitamin A-enriched diet, which also selectively normalized learning-related activity in brain regions involved in declarative memory without affecting (striatal) procedural memory (Fig. 6A-C). Interestingly, this dietary manipulation did not result in general memory enhancement: performances of younger mice were not affected nor were those of aged mice in low PI trials (STWM task) or go/no-go discrimination learning (LTDM design). Hence, although vitamin A is known to be involved in various physiological functions (for review, see Blomhoff and Blomhoff, 2006) that could possibly influence radial-maze performance, vitamin A supplementation was shown here to counteract selectively aging-associated deterioration in specific mnemonic processes.

Short-term pharmacological activation of RA signaling similarly alleviated aging-related deficits in organizational function of STWM (present study) and the flexibility property of LTDM (Etchamendy et al., 2001) without enhancing other memory performance aspects. Taken with the present demonstration of an "aged-like" LTDM deficit in $\operatorname{RAR} \beta / \operatorname{RXR} \gamma$ knock-out mice known to exhibit working memory deficit (Wietrzych et al. 2005), these findings suggest the interpretation that the cognitive benefits of the diet resulted from its preventive action against aging-related reduction of RA transcriptional function. This conclusion is in agreement with existing evidence from nutritional deprivation rodent models of retinoid signaling hypofunction: various LTDM forms were found to be deteriorated in vitamin A-deprived animals (Misner et al., 2001; Cocco et al., 2002; Etchamendy et al., 2003), although no working memory failure was detected when using a supposedly low organizationdemanding STWM task (Stancampiano et al., 2007).

\section{Hippocampal retinoid signaling and organizational capabilities}

Concerning the nature of cognitive processes involved in agingrelated deficits and their reversal by nutritional or pharmacological retinoid signaling activation, our findings pointed to STWM organization. A current literature questioning the historical consensus of STWM and LTDM system partition (for review, see Blumenfeld and Ranganath, 2007) supports the view that hippocampal and prefrontal regions are commonly involved in short-term maintenance and organization of incoming event traces. Such "short-term episodic buffer," by permitting associations and relations to be made among events, may be critical for both STWM protection against interference and the formation of unified memory representation sustaining LTDM. Within this view, we hypothesize that a critical level of retinoid-mediated transcription events may maintain specific hippocampal (and probably prefrontal) cellular properties underlying STWM organization and LTDM formation.

In conclusion, our work usefully complemented current literature on retinoid function in the adult brain. It pointed to a moderate reduction of RA-mediated nuclear events in the hippocampus as a likely explanation for aging-related deterioration of organizational processes involved in both STWM and LTDM. In humans, the demonstration that brain retinoid signaling is affected by aging remains to be done. Nevertheless, the potential relevance of our findings for understanding the molecular bases of human senescence is strengthened by a recent report on peripheral retinoid hyposignaling in aged humans (Feart et al., 2005). Furthermore, at the cognitive level, the predictive validity of our LTDM model was demonstrated recently by a translational approach. Hence, the present demonstration that nutritional vitamin A supplementation can counteract aging-related mnemonic decline in mice potentially opens a novel avenue in the search for preventing strategy against cognitive aging.

\section{References}

Anderson KD, Sengupta J, Morin M, Neve RL, Valenzuela CF, PerroneBizzozero NI (2001) Overexpression of HuD accelerates neurite outgrowth and increases GAP-43 mRNA expression in cortical neurons and retinoic acid-induced embryonic stem cells in vitro. Exp Neurol 168:250-258.

Baddeley AD, Hitch G (1974) Working memory. In: The psychology of learning and motivation: advances in research and theory, Vol 8 (Bower GH, ed), pp 47-89. New York: Academic.

Benowitz LI, Routtenberg A (1997) GAP-43: an intrinsic determinant of neuronal development and plasticity. Trends Neurosci 20:84-91.

Biewenga JE, Schrama LH, Gispen WH (1996) Presynaptic phosphoprotein B-50/GAP-43 in neuronal and synaptic plasticity. Acta Biochim Pol 43:327-338.

Blomhoff R, Blomhoff HK (2006) Overview of retinoid metabolism and function. J Neurobiol 66:606-630.

Blumenfeld RS, Ranganath C (2007) Prefrontal cortex and long-term memory encoding: an integrative review of findings from neuropsychology and neuroimaging. The Neuroscientist 13:280-291.

Boucheron C, Alfos S, Enderlin V, Husson M, Pallet V, Jaffard R, Higueret P (2006) Age-related effects of ethanol consumption on triiodothyronine and retinoic acid nuclear receptors, neurogranin and neuromodulin expression levels in mouse brain. Neurobiol Aging 27:1326-1334.

Bowles RP, Salthouse TA (2003) Assessing the age-related effects of proactive interference on working memory tasks using the Rasch model. Psychol Aging 18:608-615.

Brouillette J, Quirion R (2007) Transthyretin: a key gene involved in the maintenance of memory capacities during aging. Neurobiol Aging, in press.

Chiang MY, Misner D, Kempermann G, Schikorski T, Giguere V, Sucov HM, Gage FH, Stevens CF, Evans RM (1998) An essential role for retinoid receptors RARbeta and RXRgamma in long-term potentiation and depression. Neuron 21:1353-1361.

Cocco S, Diaz G, Stancampiano R, Diana A, Carta M, Curreli R, Sarais L, Fadda F (2002) Vitamin A deficiency produces spatial learning and memory impairment in rats. Neuroscience 115:475-482.

Cohen N, Eichenbaum H (1993) Memory, amnesia, and the hippocampal system. A Bradford Book. Cambridge, MA: MIT.

Cohen NJ (1984) Preserved learning capacity in amnesia: evidence for multiple memory systems. In: Neuropsychology of memory (Squire LRBN, ed), pp 83-103. New York: Guilford.

Craik FI, Rabinowitz JC (1985) The effects of presentation rate and encoding task on age-related memory deficits. J Gerontol 40:309-315.

Crandall J, Sakai Y, Zhang J, Koul O, Mineur Y, Crusio WE, McCaffery P (2004) 13-cis-retinoic acid suppresses hippocampal cell division and hippocampal-dependent learning in mice. Proc Natl Acad Sci USA 101:5111-5116.

Daigneault S, Braun CM (1993) Working memory and the self-ordered pointing task: further evidence of early prefrontal decline in normal aging. J Clin Exp Neuropsychol 15:881-895.

Driscoll I, Sutherland RJ (2005) The aging hippocampus: navigating between rat and human experiments. Rev Neurosci 16:87-121.

Dunnett SB, Martel FL, Iversen SD (1990) Proactive interference effects on short-term memory in rats. II. Effects in young and aged rats. Behav Neurosci 104:666-670. 
Eichenbaum H (2004) Hippocampus: cognitive processes and neural representations that underlie declarative memory. Neuron 44:109-120.

Encinas M, Iglesias M, Liu Y, Wang H, Muhaisen A, Cena V, Gallego C, Comella JX (2000) Sequential treatment of SH-SY5Y cells with retinoic acid and brain-derived neurotrophic factor gives rise to fully differentiated, neurotrophic factor-dependent, human neuron-like cells. J Neurochem 75:991-1003.

Etchamendy N, Enderlin V, Marighetto A, Vouimba RM, Pallet V, Jaffard R, Higueret P (2001) Alleviation of a selective age-related relational memory deficit in mice by pharmacologically induced normalization of brain retinoid signaling. J Neurosci 21:6423-6429.

Etchamendy N, Desmedt A, Cortes-Torrea C, Marighetto A, Jaffard R (2003a) Hippocampal lesions and discrimination performance of mice in the radial maze: sparing or impairment depending on the representational demands of the task. Hippocampus 13:197-211.

Etchamendy N, Enderlin V, Marighetto A, Pallet V, Higueret P, Jaffard R (2003b) Vitamin A deficiency and relational memory deficit in adult mice: relationships with changes in brain retinoid signalling. Behav Brain Res 145:37-49.

Feart C, Pallet V, Boucheron C, Higueret D, Alfos S, Letenneur L, Dartigues JF, Higueret P (2005) Aging affects the retinoic acid and the triiodothyronine nuclear receptor mRNA expression in human peripheral blood mononuclear cells. Eur J Endocrinol 152:449-458.

Goodman AB (1998) Three independent lines of evidence suggest retinoids as causal to schizophrenia. Proc Natl Acad Sci USA 95:7240-7244.

Goodman AB (2006) Retinoid receptors, transporters, and metabolizers as therapeutic targets in late onset Alzheimer disease. J Cell Physio 209:598-603.

Goodman AB, Pardee AB (2003) Evidence for defective retinoid transport and function in late onset Alzheimer's disease. Proc Natl Acad Sci USA 100:2901-2905.

Husson M, Enderlin V, Alfos S, Feart C, Higueret P, Pallet V (2003) Triiodothyronine administration reverses vitamin A deficiency-related hypoexpression of retinoic acid and triiodothyronine nuclear receptors and of neurogranin in rat brain. Br J Nutr 90:191-198.

Kastner P, Mark M, Chambon P (1995) Nonsteroid nuclear receptors: what are genetic studies telling us about their role in real life? Cell 83:859-869.

Keller H, Dreyer C, Medin J, Mahfoudi A, Ozato K, Wahli W (1993) Fatty acids and retinoids control lipid metabolism through activation of peroxisome proliferator-activated receptor-retinoid X receptor heterodimers. Proc Natl Acad Sci USA 90:2160-2164.

Kliewer SA, Umesono K, Mangelsdorf DJ, Evans RM (1992) Retinoid X receptor interacts with nuclear receptors in retinoic acid, thyroid hormone and vitamin D3 signalling. Nature 355:446-449.

Lane MA, Bailey SJ (2005) Role of retinoid signalling in the adult brain. Prog Neurobiol 75:275-293.

Lefebvre P, Martin PJ, Flajollet S, Dedieu S, Billaut X, Lefebvre B (2005) Transcriptional activities of retinoic acid receptors. Vitam Horm 70:199-264.

Maden M, Gale E, Zile M (1998) The role of vitamin A in the development of the central nervous system. J Nutr 128:471S-475S.

Malik MA, Blusztajn JK, Greenwood CE (2000) Nutrients as trophic factors in neurons and the central nervous system: role of retinoic acid. J Nutr Biochem 11:2-13.

Marighetto A, Etchamendy N, Touzani K, Torrea CC, Yee BK, Rawlins JN, Jaffard R (1999) Knowing which and knowing what: a potential mouse model for age-related human declarative memory decline. Eur J Neurosci 11:3312-3322.

Marighetto A, Touzani K, Etchamendy N, Torrea CC, De Nanteuil G, Guez D, Jaffard R, Morain P (2000) Further evidence for a dissociation between different forms of mnemonic expressions in a mouse model of age-related cognitive decline: effects of tacrine and S 17092, a novel prolyl endopeptidase inhibitor. Learn Mem 7:159-169.

Marill J, Idres N, Capron CC, Nguyen E, Chabot GG (2003) Retinoic acid metabolism and mechanism of action: a review. Curr Drug Metab 4:1-10. McCabe BJ, Horn G (1994) Learning-related changes in Fos-like immuno- reactivity in chick forebrain after imprinting. Proc Natl Acad Sci USA 91:11417-11421.

McCabe DP, Robertson CL, Smith AD (2005) Age differences in stroop interference in working memory. J Clin Exp Neuropsychol 27:633-644.

McCaffery P, Zhang J, Crandall JE (2006) Retinoic acid signaling and function in the adult hippocampus. J Neurobiol 66:780-791.

Mey J, McCaffery P (2004) Retinoic acid signaling in the nervous system of adult vertebrates. The Neuroscientist 10:409-421.

Mingaud F, Le Moine C, Etchamendy N, Mormede C, Jaffard R, Marighetto A (2007) The hippocampus plays a critical role at encoding discontiguous events for subsequent declarative memory expression in mice. Hippocampus 17:264-270.

Misner DL, Jacobs S, Shimizu Y, de Urquiza AM, Solomin L, Perlmann T, De Luca LM, Stevens CF, Evans RM (2001) Vitamin A deprivation results in reversible loss of hippocampal long-term synaptic plasticity. Proc Natl Acad Sci USA 98:11714-11719.

Morgan JI, Curran T (1989) Stimulus-transcription coupling in neurons: role of cellular immediate-early genes. Trends Neurosci 12:459-462.

Mosevitsky MI (2005) Nerve ending "signal" proteins GAP-43, MARCKS, and BASP1. Int Rev Cytol 245:245-325.

Moss MB, Rosene DL, Peters A (1988) Effects of aging on visual recognition memory in the rhesus monkey. Neurobiol Aging 9:495-502.

Newman J, Grace AA (1999) Binding across time: the selective gating of frontal and hippocampal systems modulating working memory and attentional states. Conscious Cogn 8:196-212.

Palha JA, Goodman AB (2006) Thyroid hormones and retinoids: a possible link between genes and environment in schizophrenia. Brain Res Brain Res Rev 51:61-71.

Penniston KL, Tanumihardjo SA (2006) The acute and chronic toxic effects of vitamin A. Am J Clin Nutr 83:191-201.

Rapp PR, Kansky MT, Eichenbaum H (1996) Learning and memory for hierarchical relationships in the monkey: effects of aging. Behav Neurosci 110:887-978.

Rosenzweig ES, Barnes CA (2003) Impact of aging on hippocampal function: plasticity, network dynamics, and cognition. Prog Neurobiol 69:143-179.

Ross AC, Zolfaghari R (2004) Regulation of hepatic retinol metabolism: perspectives from studies on vitamin A status. J Nutr 134:269S-275S.

Rowe A (1997) Retinoid X receptors. Int J Biochem Cell Biol 29:275-278.

Smith AD (1979) The interaction between age and list length in free recall. J Gerontol 34:381-387.

Stancampiano R, Carta M, Fadda F (2007) Vitamin A deficiency affects neither frontocortical acetylcholine nor working memory. NeuroReport 18:241-243.

Taneja R, Bouillet P, Boylan JF, Gaub MP, Roy B, Gudas LJ, Chambon P (1995) Reexpression of retinoic acid receptor (RAR) gamma or overexpression of RAR alpha or RAR beta in RAR gamma-null F9 cells reveals a partial functional redundancy between the three RAR types. Proc Natl Acad Sci USA 92:7854-7858.

Touzani K, Marighetto A, Jaffard R (2003) Fos imaging reveals ageingrelated changes in hippocampal response to radial maze discrimination testing in mice. Eur J Neurosci 17:628-640.

Wallenstein GV, Eichenbaum H, Hasselmo ME (1998) The hippocampus as an associator of discontiguous events. Trends Neurosci 21:317-323.

White NM, McDonald RJ (2002) Multiple parallel memory systems in the brain of the rat. Neurobiol Learn Mem 77:125-184.

Wietrzych M, Meziane H, Sutter A, Ghyselinck N, Chapman PF, Chambon P, Krezel W (2005) Working memory deficits in retinoid X receptor gamma-deficient mice. Learn Mem 12:318-326.

Winocur G (1984) The effects of retroactive and proactive interference on learning and memory in old and young rats. Dev Psychobiol 17:537-545.

Zolfaghari R, Ross AC (1995) Chronic vitamin A intake affects the expression of mRNA for apolipoprotein A-I, but not for nuclear retinoid receptors, in liver of young and aging Lewis rats. Arch Biochem Biophys 323: $258-264$. 